\title{
ANALISA KEUNTUNGAN PETERNAK SAPI POTONG DALAM PROGRAM INSEMINASI BUATAN DI KECAMATAN SELEBAR KOTA BENGKULU
}

\section{PROFIT ANAL YSIS ON CATTLE MANAGEMENT INVOLVED WITH ARTIFICIAL INSEMINATION PROGRAM IN DISTRICT OF SELEBAR BENGKULU CITY}

\author{
Yossie Yumiati ${ }^{1)}$ Heri Dwi Putranto ${ }^{2)}$ Rika Dwi Yulihartika ${ }^{1)}$ \\ 1) Prodi Agribisnis Fakultas Pertanian Universitas Dehasen Bengkulu \\ 2) Jurusan Peternakan Fakultas Pertanian Universitas Bengkulu
}

\begin{abstract}
ABSTRAK
Usaha peternakan di Indonesia dilihat dari cara pemeliharannya masih bersifat tradisional dan rata-rata usaha peternakannya masih berskala kecil sehingga menyebabkan produktifitas ternak sapi potong tergolong rendah. Solusi yang dilakukan pemerintah untuk meningkatkan produktifitas sapi potong yaitu dengan cara memperbaiki kinerja reproduksi dan menerapkan program Inseminasi Buatan (IB). Tujuan penelitian ini adalah untuk mengevaluasi aspek ekonomi melalui analisa keuntungan pada program Inseminasi Buatan (IB) yang dilakukan di Kecamatan Selebar Kota Bengkulu. Penelitian dilaksanakan pada bulan Juni sampai dengan bulan Agustus 2015. Penelitian ini dilaksanakan pada 4 desa (Pekan Sabtu, Betungan, Bumi Ayu dan Sumur Dewa) yang berada di Kecamatan Selebar Kota Bengkulu dengan mengambil 70 responden. Data yang diperoleh baik data primer maupun data sekunder dianalisa secara kualitatif dan kuantitatif. Data tersebut kemudian disajikan dalam bentuk deskriptif tabulasi dan statistik sederhana. Analisis yang dilakukan adalah dengan menghitung besarnya penerimaan dan pengeluaran serta analisa keuntungan bersih dari sapi potong yang diiukutkan dalam progam Inseminasi Buatan (IB). Berdasarkan hasil penelitian yang telah dilakukan diperoleh keuntungan atau pendapatan bersih sebesar Rp. 8.073.679 dari hasil penjualan sapi potong betina program IB rata-rata sebanyak 2 ekor dari setiap peternak, dimana jumlah rerata penerimaan peternak sebesar Rp 10,671429,- dan jumlah rerata pengeluaran sebesar Rp 2.597.750,--
\end{abstract}

Kata Kunci: Analisa Keuntungan, Kecamatan Selebar, Program Inseminasi Buatan, Sapi Potong.

\section{ABSTRACT}

Considering the low productivity of Indonesia's ruminant management, the government proposed Artificial Insemination program as one solution to enhance ruminants productivity. The purpose of this study was to evaluate the economical aspect by using a profit analysis on artificial insemination program in District of Selebar, Bengkulu city. The research was conducted during June to August 2015. There were 4 villages (Pekan Sabtu, Betungan, Bumi Ayu and Sumur Dewa) with total of 70 interviewees. Primary and secondary data were qualitatively and quantitatively analyzed. The profit and total cost were calculated. The results showed that the profit was IDR 8,073,679 (gained from 
carcass sale), the average of revenue was IDR 10,671,429 and the average of cost was IDR 2,597,750.

Keywords: Artificial Insemination Program, District of Selebar, Profit, Ruminant.

\section{PENDAHULUAN}

Dalam pembangunan pertanian dan peternakan di Indonesia masih banyak ditemukan kendala yang bersifat dominan seperti modal (capital), skala usaha dan sistem pemeliharaan. Terutama untuk peternakan ruminansia potong (sapi potong), manajemen pemeliharaan yang diterapkan masih didominasi oleh sistem pemeliharaan tradisional dan berskala kecil. Hal tersebut mengakibatkan masalah yang sangat serius yaitu tingkat produktifitas dan efisiensi ternak ruminansia potong (sapi potong) yang tergolong rendah. Hasil penelitian Kariyasa (2005) menyebutkan bahwa sebagian besar peternakan di Indonesia masih merupakan peternakan konvensional, dimana mutu bibit, penggunaan teknologi dan keterampilan peternak relatif masih rendah.

Selanjutnya Susilawati

menyebutkan bahwa salah satu upaya untuk meningkatkan produktivitas sapi potong yang rendah adalah melalui perbaikan kinerja reproduksi dan mutu genetik ternak melalui penerapan program Inseminasi Buatan (IB). Hal ini semakin memperkuat pendapat Jamaluddin (1985), 82 bahwa program IB dikembangkan untuk meningkatkan produktifitas ternak sapi potong di Indonesia.

Lebih jauh peneliti mendapatkan data bahwa penerapan program IB di Kota Bengkulu berawal pada tahun 1991, dan sampai sekarang di tahun 2014 masih terus dilaksanakan. Pada tahun 2011 program IB di Kota Bengkulu telah dilaksanakan di 8 kecamatan diantaranya di Kecamatan Selebar, Kecamatan Kampung Melayu, Kecamatan Gading Cempaka, Kecamatan Ratu Agung, Kecamatan Ratu Samban, Kecamatan Teluk Segara, Kecamatan Sungai Serut, dan Kecamatan Muara Bangkahulu (Anonimous, 2014).

Selanjutnya, peneliti mendapati bahwa telah terjadi peningkatan populasi sapi potong di Kota Bengkulu. Data tahun 2011, populasinya berjumlah 4.606 ekor dan di tahun 2013 meningkat menjadi 5.940 ekor. Menurut Anonimus (2014), kenaikan populasi ini disebabkan karena Pemerintah Daerah Kota Bengkulu melalui Dinas Peternakan Kota Bengkulu telah mengoptimalkan program IB yang setiap tahunnya disertai dengan aktifitas 
evaluasi agar populasi setiap tahunnya meningkat.

Dari aspek ekonomi dan agribisnis, program IB di Kota Bengkulu sangat bernilai ekonomis bagi pengembangan dunia pertanian dan peternakan. Keterlibatan dan interaksi antara petani/peternak dan inseminator sertabiaya produksi yang harus dikeluarkan dalam program IB di Kota Bengkulu hingga saat ini belum diketahui dan dievaluasi. Untuk menganalisis efisiensi program IB tersebut maka perlu dilakukan kegiatan penelitian tentang aspek ekonomi program IB di Kota Bengkulu sehingga diharapkan akan dapat meningkatkan efisiensi dan keberhasilan program IB dan peningkatan populasi sapi potong di Kota Bengkulu di masa mendatang.

\section{METODE PENELITIAN}

Penelitian ini dilaksanakan di Kecamatan Selebar Kota Bengkulu, dimana penentuan lokasi penelitian dilakukan dengan cara purposive sampling dengan pertimbangan berdasarkan data jumlah populasi ternak sapi potong tertinggi. Untuk Kecamatan Selebar memiliki populasi sebesar 1.581 ekor dan merupakan populasi tertinggi di Kota Bengkulu (Anonimous, 2014). Adapun desa yang terpilih ada 4 desa yaitu Desa
Pekan Sabtu, Betungan, Bumi Ayu dan Sumur Dewa.

Metode penentuan sampel yang digunakan dalam penelitian ini adalah ditentukan secara acak (simple random sampling) dan secara sengaja (purposive sampling) (Yumiati, 2012), dimana sampel diambil sebagai responden yaitu petani/peternak sebanyak 70 responden yang memiliki minimal satu ekor sapi betina yang pernah bunting dan beranak yang menggunakan IB. Adapun Penentuan jumlah responden dilakukan dengan mengunakan rumus Taro Yamane (Ridwan dan Akon, 2009) yaitu :

$$
n=0
$$

Dimana :

$\mathrm{n}=$ Jumlah sampel

$\mathrm{N}=$ jumlah populasi

$\mathrm{d}=$ presisi yang ditetapkan

Analisa keuntungan yang akan dibahas dalam penelitian ini adalah analisis pendapatan bersih yang dinyatakan dalam persamaan matematika sebagai berikut :

$$
\pi=T R-T C
$$

dimana :

$$
\begin{aligned}
& \pi \quad=\text { Pendapatan } \\
& \mathrm{TR}=\text { Total penerimaan } \\
& \mathrm{TC}=\text { Total biaya }
\end{aligned}
$$


Data penelitian berupa data primer maupun data sekunder yang bersifat kualitatif dipaparkan secara deskriptif (Yumiati, 2012). Selanjutnya data yang bersifat kuantitatif dianalisis secara statistik yaitu ditentukan nilai rata-rata kemudian diinterpretasikan menurut angka statistik tersebut.

Metode analisis data dalam penelitian ini secara deskriptif. Untuk mengetahui karakteristik responden data ditabulasi dan dianalisis secara deskriptif. Metode deskriptif dapat diartikan sebagai prosedur pemecahan masalah yang diselidiki dengan menggambarkan/ melukiskan keadaan obyek penelitian (Nawawi dan Hadary, 1995).

\section{HASIL DAN PEMBAHASAN}

\section{Penerimaan Peternak Sapi Potong Program IB}

Menurut Soekartawi (2006) Penerimaan usahaternak adalah nilai produk total usahatani dalam jangka waktu tertentu. Penerimaan yang digunakan dalam penelitian ini diperoleh dari penjualan sapi potong betina dewasa setelah dilakukan IB. Data rerata penerimaan peternak dari program IB ini dapat dilihat pada Tabel 1.

Berdasarkan Tabel 1 terlihat bahwa responden peternak memperoleh rerata produksi daging $142 \mathrm{~kg} /$ ekor sapi betina.
Hal ini dihitung dari berat karkas daging dan tulang yang bisa dijual (50\%) dari total berat sapi tersebut.

Dari rerata penerimaan yang diperoleh peternak sebesar Rp. 10.671.429,menunjukan bahwa dari sapi betina setelah IB peternak mendapatkan tambahan penerimaan sebesar $100 \%$ dari jumlah sapi betina yang sebelumnya mereka miliki. Hal sejalan dengan pendapat Jamaluddin (1985), bahwa program IB dapat dikembangkan untuk meningkatkan produktifitas ternak sapi potong di Indonesia.

\section{Pengeluaran Usaha Ternak Sapi Potong Program IB}

Pengeluaran atau biaya yang dikeluarkan peternak dalam proses produksi merupakan nilai penggunaan sarana produksi dan lain-lain yang dibebankan pada produk yang bersangkutan (Soekartawi, 2003). Struktur biaya produksi dapat dikategorikan dalam biaya variabel dan biaya tetap. Biaya variabel (VC) adalah biaya yang besar kecilnya mempengaruhi kuantitas produksi, sedangkan biaya tetap (FC) adalah biaya yang jumlahnya tidak berubah ketika kuantitas output berubah. 
Tabel 1. Rerata Penerimaan Peternak Sapi Potong Program IB di Kecamatan Selebar Kota Bengkulu

\begin{tabular}{lc}
\hline \multicolumn{1}{c}{ Uraian } & Nilai \\
\hline Rerata produksi daging $(\mathrm{Kg})$ & 142 \\
Harga jual daging $(\mathrm{Rp} / \mathrm{kg})$ & 75.000 \\
Rerata penerimaan $(\mathrm{Rp})$ & 10.671 .429 \\
\hline
\end{tabular}

Untuk biaya variabel/tidak tetap ada beberapa biaya yang harus dikeluarkan oleh peternak yang melakukan program IB pada sapi betina dewasanya antara lain :

a. Biaya straw untuk IB, dimana dalam melakukan IB keberadaan straw ini sangat penting untuk menghasilkan kebuntingan pada sapi betina. Dari Tabel 2 terlihat peternak responden ratarata mengeluarkan biaya sebesar $\mathrm{Rp}$ 13.543,- untuk pembelian straw pada 1 (satu) kali proses IB

b. Honor Inseminator IB, dimana honor inseminator ini diperoleh rerata $\mathrm{Rp}$ 287.142,- hal ini menunjukkan bahwa semakin mahal honor inseminator yang kita kita keluarkan untuk 1 kali proses IB menentukan tingkat keberhasilan IB. Hal ini sejalan dengan pendapat Lubis (2006) yang menyatakan salah satu faktor yang menentukan tingkat keberhasilan dari program IB adalah ketrampilan insiminator IB, dimana semakin terampil insiminator dalam melakukan IB semakin besar harapan sapi betina dewasa akan berhasil mengalami kebuntingan.

c. Pakan ternak, adalah konsumsi utama bagi sapi potong untuk mencapai $\mathrm{BB}$ yang optimal bagi ternak khususnya bagi ternak yang sudah dewasa. Rerata biaya untuk pakan ternak pada sapi potong ini adalah sebesar Rp 912.000,

d. Antibiotik sebagai obat pada saat ternak mengalami sakit. Rerata biaya yang digunakan untuk antibiotik adalah sebesar Rp 789.643,- cukup mahalnya harga antibiotik ini tergantung dari jenis dan banyaknya volume antibiotik yang digunakan agar masa pemulihan sapi potong tersebut lebih cepat dari penyakitnya.

e. Sumber alam suplemen digunakan untuk memenuhi kebutuhan mineral bagi ternak, dimana rerata biaya yang dikeluarkan adalah sebesar Rp.7.807,Sedikitnya kebutuhan akan mineral ini tetap dibutuhkan oleh ternak sapi potong untuk menjaga stamina hingga saat penjualan nanti. 
f. Listrik, sebagai sarana penerang kandang saat malam hari terutama bagi peternak yang memiliki populasi ternak $>3$ ekor. Adapun rerata biaya listrik yang harus dikeluarkan adalah sebesar Rp 52.957,- per bulan.

g. PDAM atau air digunakan untuk minum bagi ternak dan membersihkan kandang ternak. Biaya untuk PDAM yang harus dikeluakan peternak sebesar Rp.44.786,-perbulan.

Selengkapnya data rerata pengeluaran atau biaya produksi ternak sapi potong disajikan pada Tabel 2.

Tabel 2 menunjukkan bahwa besarnya biaya tetap (FC) untuk komponen perbaikan kandang adalah sebesar $\mathrm{Rp}$ 412.857 pertahun, dimana perbaikan kandang ini dilakukan setiap tahun untuk memberikan kenyamanan bagi ternak sapi potong khususnya untuk sapi betina yang akan di IB. Sedangkan untuk penyusutan alat ternak diperoleh sebesar Rp. 77.014,dihitung sesuai dengan jenis alat -alat yang digunakan peternak sehari-hari yang mempunyai umur ekonomis lebih dari 3 tahun. Sedangkan total biaya yang harus dikeluarkan untuk mendapatkan produksi sapi potong program IB adalah sebesar $\mathrm{Rp}$ Rp 2.597.750 per UT.

Tabel 2. Rerata Biaya Produksi Usahaternak Sapi Potong Program IB di Kec. Selebar Kota Bengkulu

\begin{tabular}{lr}
\hline \multicolumn{1}{c}{ Jenis Biaya Produksi } & Nilai (Rp) \\
\hline Biaya Tidak Tetap (VC) & 13.543 \\
a. Straw untuk IB & 287.142 \\
b. Honor inseminator & 912.000 \\
c. Pakan ternak & 789.643 \\
d.Antibiotik & 7.807 \\
e.Sumber alam suplemen & 52.957 \\
f.Listrik & 44.786 \\
g. PDAM & \\
& \\
Biaya Tetap ( FC) & 412.857 \\
a.Perbaikan Kandang & 77.014 \\
b. Penyusutan Alat Ternak & $\mathbf{2 . 5 9 7 . 7 5 0}$ \\
Total biaya (VC+FC) & \\
\hline
\end{tabular}


Analisa Keuntungan Usahaternak Sapi Potong Yang Mengikuti Program IB

Menurut Soekartawi (2003) pendapatan adalah selisih antara penerimaan dan total biaya yang dikeluarkan. Bagi seorang peternak analisa pendapatan atau keuntungan memberikan bantuan untuk mengukur apakah kegiatan usahaternak yang dilakukan pada saat ini berhasil atau tidak.

Adapun rerata pendapatan yang diterima peternak sapi potong program IB di Kecamatan Selebar dapat dilihat pada Tabel 3.

Tabel 3 menunjukkan bahwa pendapatan bersih yang diperoleh dari penjualan sapi potong betina program IB adalah sebesar Rp. 8.073679,-. dengan rata-rata sapi potong betina IB yang berjumlah 2 ekor per responden. Berdasarkan nilai pendapatan bersih yang diperoleh peternak sapi potong yang melakukan program IB dikategorikan menguntungkan dan dapat meningkatkan pemasukan peternak. Selain itu juga dengan meningkatnya populasi sapi potong sejalan dengan pendapat Susilawati (2011) menyebutkan bahwa salah satu upaya untuk meningkatkan produktivitas sapi potong yang rendah adalah melalui perbaikan kinerja reproduksi dan mutu genetik ternak melalui penerapan program Inseminasi Buatan (IB) dalam rangka memenuhi konsumsi masyarakat akan produksi daging dari sapi potong.

Tabel 3. Rerata Pendapatan Peternak Sapi Potong Program IB di Kecamatan Selebar Kota Bengkulu

\begin{tabular}{lc}
\hline Uraian & Nilai (Rp) \\
\hline $\begin{array}{l}\text { Penerimaan } \\
\text { Total Penerimaan (TR) }\end{array}$ & 10.671 .429 \\
Biaya Produksi & 2.107 .879 \\
a. Biaya Variabel (VC) & 489.871 \\
b.Biaya Tetap (FC) & 2.597 .750 \\
Total Biaya $(\mathrm{TC})=(\mathrm{VC})+(\mathrm{FC})$ & 8.073 .679 \\
\hline Keuntungan $(\mathrm{TR})-(\mathrm{TC})$ & \\
\hline
\end{tabular}




\section{SIMPULAN}

Pendapatan rerata yang peroleh peternak sapi potong betina dewasa di Kecamatan Selebar Kota Bengkulu yang diikutkan dalam program IB adalah sebesar Rp. 8.073.679. Total penerimaan sebesar Rp. 10.671 .429 ,- $^{-}$serta total biaya yang dikeluarkan peternak sebesar Rp. 2.597.750,-

\section{DAFTAR PUSTAKA}

Anonimous. 2014. Rekapitulasi Jumlah Sapi Potong dan Kerbau Hasil Sensus Pertanian. Dinas Peternakan Kota Bengkulu. Bengkulu.

Jamaluddin, M.M. 1985. Evaluasi Hasil Kebuntingan Sesudah Pengobatan Hipofungsi Ovarium dan Corpus Luteum Presisten pada Sapi Perah di Kecamatan Pujon, Malang. Fakultas Kedokteran Hewan Institut Pertanian Bogor. Bogor.

Kariyasa. 2005. Manajemen Sapi Potong. Universitas Sumatra Utara. Sumatra Utara.

Lubis, N.M. 2006. Tingkat Keberhasilan Inseminasi Buatan Pada Ternak Sapi di Kecamatan IV Angkat Candung Kabupaten Agam.
Fakultas Peternakan Universitas Andalas. Padang.

Nawawi, H. dan M. Hadari. 1995. Instrumen Penelitian Bidang Sosial. Gadjah Mada University Press. Yogyakarta.

Ridwan dan Akon. 2009. Rumus dan Data Dalam Analisis Statistika Untuk Penelitian (Administrasi Pendidikan Bisnis Pemerintah Sosial Kebijakan Ekonomi Hukum Manajemen Kesehatan). Penerbit Alfabet. Bandung.

Soekartawi, A, 2003. Prinsip Ekonomi Pertanian. PT. Rajagrafindo Persada. Jakarta

Soekartawi, A, 2006. Ilmu Usaha Tani dan Penelitian Untuk Pengembangan Petani Kecil. Universitas Indonesia Press. Jakarta

Susilawati, T. 2011. Tingkat keberhasilan inseminasi buatan dengan kualitas dan deposisi semen yang berbeda pada sapi Peranakan Ongole. Jurnal Ternak Tropika 12(2): 1524.

Yossie, Y. 2012. Analisis Faktor-Faktor yang Mempengaruhi Keputusan Domestikasi Ayam Brugo Sebagai Upaya Konservasi Plasma Nutfa Bengkulu di Kecamatan Bermani Ulu Kabupaten Rejang Lebong. Bengkulu. Thesis Program Studi Pascasarjana sumberdaya Alam dan lingkungan Fakultas Pertanian Universitas Bengkulu. 